\title{
Educação nutricional em serviços públicos de saúde
}

\author{
Nutritional education in public health services
}

Maria Cristina Faber Boog 1

\footnotetext{
1 Departamento de Enfermagem, Faculdade de Ciências Médicas, Universidade Estadual de Campinas. C. P. 6111, Campinas,SP 13083-970, Brasil.
}

\begin{abstract}
The purpose of this study was to discuss the implementation of nutritional education in public heal th servi ces from the perspective of health professi onals (physi cians and nurses) working in them. The study was conducted in the Muni cipality of Campinas, São Paul o State, Brazil, from October 1993 to July 1995, using action-based research methodology. The results describe the construction of nutritional knowledge in training and professional institutions; behavior towards food-related problems in daily professional experience as compared to personal life; the contradiction between the apparentl y trivial act of eating and the compl exity of dietary problems; the interface between the acceptance of this work and the incorporation of nutritional education activities and their actual institutionalization; and health professi onals' opinions concerning situations permeating the implementation of activities. The paper concludes by re ferring to the need to implement nutritional education activities, difficulties experienced by physi cians and nurses in approaching nutritional problems, and the importance of including nutrition in the curricula of health courses.
\end{abstract}

Key words Health Education; Nutritional Education; Health Services; Health Personell; Nutrition

Resumo Este estudo objetivou discutir a implementação deativi dades de edu cação nutricional em serviços públi cos de saúde, valen do-se da visão de médicos e enfermei ros que atuam nesses serviços. A pesquisa foi desenvolvida em Campinas, Estado de São Paulo, Brasil, entre outubro de 1993 e jul ho de 1995, utilizando-se o método da pesqui sa-ação. Os resultados descrevem a construção do saber sobre nutrição através das institui ções formadoras e profi ssi onai s; a conduta adotada em face dos probl emas relati vos à al imentação no coti di ano profi ssi onal em contraposição ao enfrentamento dos mesmos no coti diano pessoal; a contradição existente entre a aparente banal i dade do ato da al imentação em contraposi ção à complexidade dos problemas al imentares; a trajetória entre a acei tação do trabal ho e incorporação das ações de educação nutricional ea efetiva institucionalização dos mesmos; a visão dos profissionais diante de si tuações que permeiam a implementação das ações nesse campo. As conclu sões referem-se à necessi dade de impl ementação de atividades de educação nutricional nos serviços de saúde, às dificuldades dos profissionais para abordar problemas rel ativos à nutrição e à necessi dade de discutir o ensino de nutrição nos cursos da área da saúde.

Palavras-chave Educação em Saúde; Educação Nutricional; Serviços de Saúde; Pessoal de Saúde; Nutrição 
Introdução

É fato incontestável a importância da alimentação saudável, completa, variada e agradável ao paladar para a promoção da saúde, sobretudo dos organismos jovens, em fase de desenvolvimento, e para a prevenção e controle de doenças crônicas não transmissíveis, cuja prevalência vem aumentando significativamente. No Brasil, a prevalência de obesidade dobrou ao longo de 15 anos. Monteiro et al. (1995a) referem que a razão entre a prevalência de desnutrição e de obesidade foi dramaticamente afetada entre 1974 e 1989. Em 1974, havia, na população infantil, mais de quatro desnutridos para um obeso e, em 1989, essa relação caiu para dois desnutridos para um obeso. Na população adulta, houve inversão de valores: em 1974, havia um e meio desnutrido para um obeso, enquanto, em 1989, a obesidade excedeu duas vezes a desnutrição. Monteiro et al. (1995b) dizem que o "conceito equi vocado da inevitabili dade das doenças crônicas certamente está na base da ausência ou incipiência das ações públicas di rigidas ao controle, por exemplo, do tabagi smo, do al coolismo e da obesidade". M onteiro et al. (1995a) recomendam que se reserve "lugar de destaque a ações de educação em al imentação enutri ção queal cancem de modo eficaz, todos os estratos econômicos da população".

A educação nutricional tem um papel importante também em relação à promoção de hábitos alimentares saudáveis desde a infância. Cerqueira (1985) a considera medida de alcance coletivo com o fim primordial de "proporcionar os conhecimentos necessários ea moti vação col etiva para formar atitudes e hábitos de uma al imentação sadi a, compl eta, adequada evariada". Infelizmente, as experiências documentadas sobre os programas e as atividades de educação nutricional no Brasil são em número exíguo, e raríssimas as iniciativas junto à rede básica de saúde (Boog, 1997), motivo pelo qual não se encontra, na literatura, dados relativos a resultados de intervenções. Encontram-se, sim, estudos diagnósticos, analisando possibilidades de intervenções educativas. Diferentes autores vêm apontando o fato de que, "mesmo em condições macroambi entais i gualmente desfavoráveis, a desnutrição energéticoprotéica não ocorre em todos os indi víduos, indicando a coexistência de outros fatores" (Dasen \& Super apud Solymos, 1997; Nóbrega \& Campos, 1996). Esses fatores foram estudados por Solymos (1997), que aponta como elementos importantes para o enfrentamento de situações adversas, entre outros, o incremento das redes de relacionamentos através de atendimentos especializados e os relacionamentos de ajuda. Assim, as atividades de educação em saúde, direcionadas por exemplo à área materno-infantil, dentro de uma proposta pedagógica de ensino baseada na situação concreta de vida, desempenham estes papéis, sobretudo quando realizadas em grupo.

O interesse pela educação nutricional surgiu na década de 40, e a primeira publicação da Organização Mundial da Saúde (OMS) a respeito data do início dos anos 50 (Ritchie, 1951). Antes disso, teve influência relevante o Comitê sobre Hábitos Alimentares, do Conselho Nacional de Pesquisa dos Estados Unidos da América, que reuniu nutrólogos, antropólogos, psicólogos e educadores com o objetivo de pôr em comum seus conhecimentos, buscando métodos mais eficazes para modificar hábitos alimentares.

No Brasil, à esta época, o interesse pela nutrição surgia com Josué de Castro, que foi sempre um defensor do planejamento econômico e da reestruturação agrícola para solucionar o problema da fome, porém sem descartar o papel da educação (L'Abbate, 1982). A orientação nutricional da população trabalhadora gozava de status privilegiado e era vista como um dos pilares dos programas governamentais de proteção ao trabalhador.

$\mathrm{Na}$ década de 70 , a política alimentar no Brasil, que, até então, fora centrada no binômio alimentação-educação, tomou novo rumo em face dos resultados de pesquisas realizadas na época (Alves, 1977; Viacava et al., 1983), que mostraram que o principal obstáculo à alimentação adequada é a renda e que somente transformações estruturais no modelo econômico teriam efetivamente poder de resolutividade diante dos problemas alimentares. Assim, o binômio anterior foi substituído pelo binômio alimentação-renda, e a educação nutricional partiu para o 'exílio' como muito bem referiram Castro \& Peliano (1985).

Embora tendo caído em descrédito, a disciplina Educação Nutricional foi mantida nos cursos de Nutrição, muito mais como um apêndice da nutrição em saúde pública, do que como um campo específico de conhecimento, sofrendo as dificuldades decorrentes da falta de bibliografia e de professores especial izados.

Porém, entre a ingênua perspectiva de resolver o problema da fome e da desnutrição por meio da educação e a atitude oposta de concentrar todos os esforços unicamente na luta por transformações estruturais, persiste uma demanda por educação nutricional como recurso para a nutrição clínica e dietoterapia.. 
Encontra-se referência à implantação de serviços de nutrição junto a ambulatórios, mas estes nem sempre fazem referência a propostas educativas. O nutricionista, embora definido como profissional da saúde, está até hoje muito ausente da rede básica de saúde, pois apenas 3\% a $7 \%$ dos profissionais formados vão para esta área, segundo diferentes autores (Boog et al., 1988; Bosi, 1996; Modesto, 1980).

Behar (1991), em palestra proferida no Simpósio Latino-Americano de Nutrição, realizado em São Paulo, expressou descrédito a respeito dos programas verticais, dizendo que a responsabilidade direta dos profissionais da área de nutrição, com possibilidade de ação efetiva, está nos serviços de saúde.

O confronto dessa posição de Behar com a constatação da quase inexistência do profissional nutricionista na rede básica de saúde levou à realização de uma pesquisa com o propósito de verificar qual é a percepção dos profissionais que tradicionalmente atuam na linha de frente dos serviços de saúde - médicos e enfermeiros - a respeito do desenvolvimento de ações referentes à educação nutricional e da sua percepção sobre as questões pertinentes a este campo de conhecimento.

\section{Materiais e métodos}

O método empregado foi o da pesquisa-ação, adaptado de Thiollent (1992), definido para a finali dade deste estudo como uma estratégia de pesquisa, na qual existe uma ação por parte do investigador, com vistas à transformação da realidade concreta. Através desta, ele pretende também aumentar o seu conhecimento e a consciência dos sujeitos pesquisados a respeito da problemática estudada, envolvendo a prestação de serviço, a observação sistemática, o diálogo com os sujeitos pesquisados, que acontece tanto em situações informais, como em situações planejadas, sob a forma de entrevistas, e o retorno aos sujeitos da elaboração teórica que o pesquisador faz baseado nos dados coletados.

O estudo, realizado em dois serviços de saúde do Município de Campinas (São Paulo, Brasil), foi desenvolvido em quatro etapas. $\mathrm{Na}$ primeira, fase exploratória, a pesquisadora, no caso a própria autora do trabalho, permaneceu na instituição para tomar contato com o espaço onde aquele seria desenvolvido, conhecer as equipes, programas e serviços prestados. $\mathrm{Na}$ segunda, prestação de serviços, a pesquisadora passou a trabalhar dois períodos por semana em cada uma das instituições, dentro da sua especialidade, desenvolvendo atividades de educação nutricional mediante atendimento individual ou em grupo. Durante a prestação de serviço, foram feitas a observação sistemática, cujos dados eram registrados em um caderno de campo, e as entrevistas semi-estruturadas com médicos e enfermeiros que estavam mais ligados ao trabalho desenvolvido pela pesquisadora. Ao todo, foram entrevistadas nove enfermeiras e oito profissionais da área médica, sendo quatro médicos e quatro médicas. Na terceira etapa, discussão dos resultados preliminares com os sujeitos, foi elaborado um livreto, denominado Discutindo Nutrição, por meio do qual a pesquisadora encaminhou aos entrevistados dados levantados nas entrevistas e algumas análises preliminares. Junto foi enviado um questionário no qual os sujeitos registraram suas opiniões sobre a participação na pesquisa e sobre as análises feitas. A quarta etapa, teorização, consistiu em reportar os achados à teoria.

O estudo exigia um referencial para análise que oferecesse uma estrutura conceitual abrangente. Tal referencial foi encontrado no campo da sociologia do conhecimento, particularmente na obra de Berger \& Luckmann (1985), A Construção Social da Realidade. O método de análise empregado foi de natureza qualitativa, baseado em Bardin (s/data), Haguette (1995), L'Abbate (1990), Lüdke \& André (1986), Minayo (1993) e Thiollent (1982, 1992). O processamento dos dados foi realizado através de análise de conteúdo, na qual se trabalha com informações fatuais, perceptivas, opinativas e de atitudes (Thiollent, 1982). Por ser um método qualitativo, ele prescinde de anál ise estatística.

\section{Resultados e discussão}

As percepções dos médicos e enfermeiros sobre o tema foram organizadas em torno de quatro eixos: construção do saber sobre nutrição, impasses da cotidianidade, trajetória para a institucionalização e contradições da educação nutricional.

\section{Construção do saber sobre nutrição}

Considerando que a nutrição é a base sobre a qual se desenvolvem todos os processos fisiológicos e patológicos, que nenhum fenômeno orgânico normal ou anormal ocorre sem que haja um componente nutricional envolvido e ainda que o papel primordial da nutrição é o da promoção, manutenção e recuperação da saúde, pressupõe-se a necessi dade de um ade- 
quado preparo dos profissionais da área da saúde em relação ao assunto.

Admitindo que o conhecimento dos médicos e enfermeiros sobre nutrição teria sido, primordialmente, adquirido por intermédio das instituições formadoras, seguido da vivência no cotidiano profissional e sofrendo a influência das instituições ligadas à profissão, pesquisou-se, então, a visão dos profissionais a respeito da construção do seu saber sobre nutrição, desde o curso de graduação.

Os médicos não comentaram quase nada a respeito do ensino de nutrição durante a sua graduação, porque, de fato, ele não ocorreu e, por isso, manifestam pouco interesse em integrar informações relativas a esta área de conhecimento. Reconhecem que houve deficiência na formação e ressentem-se da precariedade e inconsistência dos conhecimentos nesse campo. As informações adquiridas em outras disciplinas ou pela prática não chegam a ser sistematizadas, o que faz com que não haja uma visão global sobre o assunto. Dos oito médicos entrevistados, sete, formados na década de 80, não tiveram disciplina específica na área durante o curso de graduação. Apenas um, formado no final da década de 60 , lembrou-se de ter tido aulas sobre nutrição, porém não soube informar se havia uma disciplina específica ou não.

Todas as enfermeiras entrevistadas tiveram disciplina específica na graduação, pois, até 1994, ela integrava o currículo mínimo, obrigatoriedade abolida através da Portaria 172/ 94 do Ministério da Educação e do Desporto (Boog et al., 1995). Apesar de a situação do ensino nos cursos de enfermagem ser diferente, o resultado prático é semelhante. Sete, das nove enfermeiras entrevistadas, avaliaram o ensino negativamente, fazendo críticas ao docente, à metodologia, à falta de aplicação prática dos conhecimentos, ao tipo de conteúdo ministrado e, em alguns casos, ela se tornou alvo de ironia ou chacota. Criticaram, também, o fato de o ensino ter sido muito voltado a questões pontuais, específicas ou "macetes", como referiu uma das enfermeiras entrevistadas.

O ensino de nutrição nos cursos de Medicina é uma questão relevante que merece ser discutida. Em 1985, a Academia Nacional de Ciências dos Estados Unidos publicou um relatório contendo uma avaliação do ensino daquela disciplina nas escolas médicas, no qual se concluía que, quando ensinada, ela o é de forma inadequada, que as escolas médicas atribuemIhe pouca importância na organização dos currículos e que ainda existem várias barreiras à introdução da matéria (Winick, 1993). Em 1994, A Associação Americana de Dietética (Ameri- can Dietetic Association, 1994), posicionou-se a respeito, recomendando formalmente "a inclusão da educação em nutrição como um componente essencial de todos os níveis de educação médica", com base nos seguintes argumentos: em primeiro lugar, oito das dez primeiras causas de morte nos Estados Unidos tem relação com a dieta; em segundo, as intervenções em nutrição diminuem o risco de complicações de várias enfermidades; em terceiro lugar, elas diminuem o custo de outros itens de assistência à saúde.

Dessa argumentação, pode-se depreender que seria oportuno às instâncias representati vas das escolas médicas discutir a necessidade de introduzir o ensino de nutrição nos cursos de Medicina. Esta é uma discussão que não pode ser abandonada por aqueles que acreditam na formação dos profissionais de saúde voltada aos interesses e anseios da sociedade.

Com a última alteração do currículo mínimo dos cursos de Enfermagem, fica facultado a estes oferecer ou não disciplinas na área de nutrição (Boog, 1995). Esse novo currículo pode apontar para um retrocesso acadêmico na área de nutrição, que, em vez de ver expandir o seu interesse científico e aplicação em prol da sociedade, novamente a vê subtraída da formação de um profissional de saúde. Se efetivamente isso ocorrer, os enfermeiros formados de agora em diante não mais discutirão em sua formação esse aspecto da saúde, básico para a vida, e tratarão os problemas de alimentação e nutrição de forma estritamente empírica. Compete à Academia, por intermédio de seus especialistas na área, discutir as razões pelas quais a nutrição tem sido tão alijada do ensino da saúde e envidar esforços a fim de alterar essa trajetória.

Com relação à vivência profissional, três podem ser as fontes de informação e atualização: leituras, instituições profissionais, além da própria experiência prática.

Entre as enfermeiras, as leituras foram citadas em primeiro lugar, vinculadas à necessidade de atendimento a pacientes portadores de patologias específicas. Entretanto, é notório, tanto nos depoimentos dos médicos, como nos das enfermeiras, a dificuldade de encontrar material sobre nutrição adequado aos problemas relativos à al imentação que se apresentam na prática profissional.

Com relação à influencia das instituições profissionais, os médicos informaram observar um interesse incipiente em al gumas áreas, como cardiologia, endocrinologia e ortomolecular. Para eles, a nutrição adquire importância, à medida que venha a constituir mais uma tec- 
nologia de cura. As instituições ligadas à enfermagem voltam-se eventualmente às questões de nutrição para relacionar estas a problemas sociais.

Impasses da cotidianidade

Com a finalidade de analisar as condutas dos profissionais de saúde em face de problemas relacionados à alimentação, trazidos pelos clientes, perguntou-se aos entrevistados como se dá a abordagem dessas questões nas consultas e quais as dificuldades encontradas na prática para tratar o problema.

Dos oito médicos entrevistados, apenas um afirmou não abordar questões relativas à nutrição em clínica médica, embora o faça em seu consultório onde atua como pediatra, e um referiu abordá-las às vezes, enquanto os outros seis responderam afirmativamente. Entre as enfermeiras, duas referiram abordar tais questões apenas às vezes e as outras sete afirmaram que costumam mencionar o assunto nas consultas de enfermagem. As questões de alimentação acabam por vir à baila, mesmo não fazendo parte da anamnese.

A solicitação de atuação específica em relação à nutrição é muito mais intensa para as enfermeiras do que para os médicos, porque, além de serem questionadas a esse respeito pelos pacientes, recebem solicitações dos próprios médicos, que lhes del egam a responsabilidade da orientação nutricional. Perguntadas sobre as experiências que tiveram a esse respeito, responderam abrindo um amplo leque de causas de demanda: diabetes, feridas, ostomias, hipertensão, hipercolesterolemia, hi pertrigliceridemia, anemia, doença de Chron, obesidade, osteoporose, pacientes em tratamento com bota d'Unna, pré-natal, distúrbios da menopausa e paralisia cerebral.

Apenas um médico e duas enfermeiras afirmaram não encontrar dificuldade para abordar questões relativas à nutrição. As principais dificuldades mencionadas pelas enfermeiras diziam respeito à falta de embasamento teórico eà situação econômica dos pacientes. Relataram ainda a dificuldade de realizar orientação nutricional com base em tabelas trazidas e impostas pelos médicos nos serviços. Mas, mesmo quando consideram este material inadequado, não chegam a discuti-lo com os médicos. Estes também mencionaram a falta de embasamento teórico sobre o assunto, o exíguo tempo de consulta, dificuldades relativas à técnica de abordagem do problema al imentar, "medo" de que o paciente não siga a orientação e "falta de si nceridade" do paciente ao dar informações sobre consumo alimentar (Boog, 1997).

É interessante ainda salientar o conflito pessoal como uma dificuldade para abordar questões relativas à nutrição. Embora esse aspecto tenha sido mencionado apenas uma vez nas entrevistas, ele pode ser considerado como uma dificuldade primeira. No dia a dia, em diálogos informais, essa é uma questão que surge com muita frequência: o descrédito dos profissionais de saúde diante da orientação nutricional, em razão de seus próprios problemas e dificuldades para mudar o comportamento alimentar.

As questões alimentares tornam-se foco de atenção na consulta médica quando o problema que levou o paciente ao consultório tem relação específica com fatores nutricionais. Em virtude da alta demanda de consultas médicas para controle de doenças crônicas não transmissíveis, a questão nutricional obrigatoriamente permeia o tratamento, e, dependendo da especialidade, torna-se até mesmo um dos pilares deste, como é o caso do diabetes.

Dos depoimentos emerge uma contradição básica: a aparente banalidade do ato da alimentação contrapõe-se à complexidade dos problemas alimentares. Quando se trabalha tecnicamente com questões que pertencem à esfera do cotidiano, a visão construída na cotidianidade tende a predominar sobre a visão que pertence à esfera do conhecimento científico (Berger \& Luckmann, 1985). Dessa forma, não basta possuir o conhecimento, é preciso levá-lo ao nível da análise crítica do próprio hábito e das próprias representações relativas ao ato da alimentação. As respostas dadas pelos profissionais indicam de que o ensino de nutrição não consegue romper com o conhecimento fatual do senso comum.

A esse respeito é interessante observar a experiência de Chery et al . (1987). Estes autores realizaram um estudo verificando o nível de conhecimentos e a prevalência de crenças infundadas (misconceptions) entre estudantes universitários canadenses durante um período de 13 anos, baseando-se na hipótese de que um incremento de conhecimentos não necessariamente reduz a prevalência de crenças. Efetivamente, a pesquisa demonstrou que o nível de con hecimentos cresceu entre 1971 e 1984, enquanto a prevalência de crenças encontrada em 1984 era similar àquela observada em 1971. Os cursos de Nutrição não estavam conseguindo trabalhar as atitudes dos alunos a fim de torná-los suficientemente críticos em relação às suas próprias crenças; assim, o senso comum construído no cotidiano era o critério primordial na análise das situações-problema. 
Essa impermeabilidade das crenças pessoais ao conhecimento técnico encontra explicação nos fatores antropológicos e psicológicos da alimentação. O ensino de nutrição que não enfrentar esse desafio, não possibilitará ao aluno desenvolver senso crítico para avaliar esses fatos e certamente não o tornará suficientemente sensível à compreensão dos problemas nutricionais individuais. Heimburger et al . (1994) relatam uma experiência feita na Universidade do Alabama, com esse objetivo. Para aprimorar o curso de Introdução à Nutrição Clínica, foi proposto aos estudantes fazerem a análise da composição de suas próprias dietas através do computador, exercício que foi, posteriormente, repetido ao término do curso. Os autores verificaram que a ingestão de lipídios, gordura saturada e colesterol havia sido reduzida; que a ingestão de vitamina $C$ excedeu as recomendações, indicando um aumento no consumo de frutas e hortaliças. Com isso, eles concluíram que a auto-avaliação dietética no ensino de Nutrição Clínica nas escolas médicas é de grande valia.

As dificuldades que os médicos e enfermeiros encontram para lidar com as questões de alimentação decorrem não só do seu desconhecimento sobre o assunto, mas também da complexidade do problema na dimensão do cotidiano e dos conflitos que emergem da contradição entre o que se sabe e o que se pensa, com o que se sente e se faz na prática. Resulta daí o não-reconhecimento dos problemas alimentares como dados trabalháveis pelas equipes de saúde. Via de regra, tais problemas são percebidos como questões do cotidiano, fora do âmbito das ações de saúde. Não se considera, também, a existência do nutricionista como o profissional tecnicamente habilitado para lidar com essas questões (Boog, 1996).

Trajetória para a institucionalização

Pelos depoimentos colhidos, percebe-se a existência de três tipos de dificuldades em identificar tarefas e papéis inerentes à educação e orientação nutricional.

Em primeiro lugar, médicos e enfermeiros se vêem, na sua prática profissional, na contingência de dar orientação sobre alimentação. Se por um lado essas orientações não chegam a configurar efetivamente uma educação nutricional, por outro, cria-se a ilusão de que o problema está sendo tratado. Em segundo lugar, quando se pergunta a médicos e enfermeiros qual é o local onde cabe desenvolver atividades de educação nutricional, os profissionais respondem de forma muito vaga ou procuram argumentos que encaminhem o problema à responsabilidade da escola e não dos serviços de saúde. Em terceiro lugar, observou-se que educação nutricional é, para os entrevistados, uma entidade tão abstrata, que questões como responsabilidade, local ou potencial de resolutividade carecem de sentido. Educação nutricional tem um certo valor para eles enquanto idéia, porém percebe-se a inconsistência desta quando se procura reportá-la a uma prática profissional que envolve responsabilidade, espaço e objetivos. Nas falas de alguns entrevistados, percebe-se que a idéia abstrata de educação nutricional ganha significado prático na pessoa de um nutricionista que então faria este trabalho. Por outro lado, há os que vêem o nutricionista apenas como o detentor de um conhecimento técnico, muito específico, que deve ser repassado a outros profissionais que farão o atendimento.

A cidade de Campinas conta com um curso de Nutrição vinculado à Pontifícia Universidade Católica de Campinas, funcionando desde 1978 e formando profissionais desde 1982, mas até 1999 nenhum profissional nutricionista foi contratado para a rede básica de saúde no município. Perguntou-se aos entrevistados por que, na sua visão, até o presente momento, o trabalho do nutricionista não foi incorporado aos serviços de saúde. Surgiram dois tipos de resposta: a visão técnica e a visão política da questão. A visão técnica corresponde à crença nos resultados da conscientização dos médicos sobre os problemas de nutrição, para que venham a reconhecer o papel do nutricionista, bem como na eficácia das experiências-piloto e da divulgação do trabalho. Por outro lado, a visão política corresponde à convicção de que está em jogo uma questão de poder e que a intervenção deve ser de ordem política. Se a categoria dos nutricionistas tem convicção de que o seu instrumental teórico-prático habilita-os a exercer bem esse papel e que ele é relevante para a sociedade, essa luta deve ser empreen dida. Assim colocada, a luta da categoria torna-se uma mediação entre as necessidades sociais eas instâncias que deliberam sobre programas e recursos para a saúde.

\section{Contradições da educação nutricional}

Os depoimentos dos entrevistados são indicativos da percepção da necessidade de uma atuação mais direta sobre os problemas de alimentação, o que, por sua vez, remete à al ternativa da educação nutricional. Recomenda a Organização Mundial da Saúde (WHO, 1989) que os países adotem estratégias de preven ção pri- 
mária para modificar a dieta, a fim de alcançar ingestas de nutrientes dentro dos limites aconselhados. As recomendações específicas referem-se à diminuição de ingestão de gorduras, aumento de alimentos amiláceos e uma ingestão considerável de frutas e hortaliças. As mudanças no padrão de alimentação da população urbana brasileira, estudadas por Mondini \& Monteiro (1994), evidenciam tendência exatamente contrária. A participação de lipídios no consumo calórico total, no Brasil, aumentou de $26 \%$ para 29,8\% entre 1962 e 1988 ; a de carboidratos diminuiu, de $62,1 \%$ para $57,4 \%$, e a de frutas caiu de $3,8 \%$ para $2,5 \%$, no mesmo período. Estes autores concluem dizendo que as autoridades sanitárias brasileiras deveriam consignar prioridade crescente à relação dietasaúde, seja implementando medidas que visem à conscientização da população para o problema, seja trabalhando junto a outros setores do governo no sentido de garantir, para todos, a oferta de uma alimentação saudável e o acesso a ela.

É notório que a educação nutricional ressurge timidamente após um 'exílio' de quase vinte anos, mas as ações desenvolvem-se sobre um palco de contradições. Em um extremo a fome, em outro os excessos alimentares, mesmo entre as classes sociais desfavorecidas, onde surgem como resposta à penúria experimentada em outras épocas. Em um pól o o problema social analisado do ponto de vista coletivo e populacional demandando políticas públicas e sociais adequadas à obtenção de uma efetiva segurança alimentar e nutricional, e em outro os problemas humanos vistos em suas particularidades, que requerem do técnico ação singular, encontrando em cada usuário dos serviços de saúde, ao mesmo tempo, o cidadão que tem direitos e deveres e o homem que busca assistência. No âmbito da educação em saúde, nos serviços públicos de saúde, as propostas amplas, voltadas à promoção da saúde, com "prioridade para as atividades preventivas", como consta da Constituição Brasileira (artigo 198, item II), conflitam com a realidade dos serviços, onde o cidadão busca prioritariamente tratamento para as doenças. Para o profissional nutricionista também há contradições: de um lado, a exigência de aprimoramento científico e tecnológico (o status de usar computador para calcular dietas!), de outro, o desafio de pisar o chão de um centro de saúde e, acreditando no mais antigo recurso da educação a palavra -, dar respostas significativas a essa legião de diabéticos, hipertensos, obesos, cujos hábitos seculares só são questionados e modificados pel os comerciais de televisão, que apre- sentam como modelos os hábitos alimentares das classes privilegiadas. Aos cursos de Nutrição cabe decidir entre manter a educação nutricional como um apêndice da disciplina Nutrição em Saúde Pública, ou entendê-la como um vasto campo de conhecimento aplicável a diferentes áreas de atuação do nutricionista, merecedora de verbas para a pesquisa, professores capacitados especificamente para ministrá-la e campos de prática condizentes com as propostas da disciplina.

Todos os fatos podem ser analisados sob a perspectiva da universalidade, da particularidade e da singularidade (Lourau, 1975). O hábito alimentar tem uma dimensão social advinda do modo de produção da sociedade, da inserção e das relações dos indivíduos no mercado de trabalho e da classe social a que pertencem; mas ele tem também aspectos que contradizem os aspectos universais, aspectos estes que advêm da história pessoal de cada indivíduo. Além disso, os problemas alimentares não são nem só universais, nem só individuais - eles precisam ser analisados dialeticamente na sua singularidade. Este é um dos papéis da educação nutricional. Essas contradições tornam difícil o entendimento das possibilidades concretas das ações educativas.

É evidente que o campo da educação nutricional transcende muito a experiência aqui relatada, porém é incontestável o fato de que ela retorna do exílio. Resta discutir que encaminhamento se dará a ela agora.

\section{Conclusões}

Convém ressaltar que em um trabal ho no qual se emprega o método da pesquisa-ação, os resul tados podem ser considerados sempre provisórios (Haguette, 1995), pois a finalidade dele é saber mais sobre a realidade, para agir sobre ela, transformando-a.

Os itens enumerados a seguir foram dispostos a fim de expor primeiramente as três conclusões referentes à implementação de atividades de educação nutricional nos serviços de saúde. Depois, vêm as conclusões relativas à percepção dos problemas alimentares, bem como da influência do cotidiano pessoal sobre ela, influência das instituições formadoras e instituições profissionais. Em seguida, as conclusões de números VII e VIII referem-se à percepção da necessidade de interven ção do profissional nutricion ista neste campo. Finalmente, vêm duas conclusões referentes ao ensino de nutrição nos cursos superiores da área da saúde e ao ensino de educação nutricional. 
I) A educação nutricional deve estar presente em todos os níveis de atenção à saúde.

II) Programas de educação nutricional são necessários para enfrentar o atual quadro de morbi-mortalidade da população, que ten de a agravar-se pela tendência que vem sendo observada nos padrões de consumo de alimentos.

III) Há receptividade, interesse e necessidade social de ações de educação nutricional, porém inexiste o espaço institucional, entendido por cargos e funções nas organizações de saúde.

IV) Os médicos e enfermeiros encontram dificuldade para lidar com problemas alimentares, quer sejam dos pacientes, quer sejam próprios. É imprescindível a busca, por meio da pesquisa, de métodos e técnicas que façam emergir tais problemas, permitindo, assim, a busca de soluções para o seu enfrentamento.

V) Médicos e enfermeiras têm dificuldade em identificar problemas alimentares. Freqüentemente, tendem a considerar estes como uma questão do cotidiano, cujo tratamento foge aos objetivos dos serviços de saúde, ou a confundi-los com problemas econômicos, atribuindo sempre a estes a causa dos problemas alimentares de modo geral.

VI) Médicos e enfermeiras têm formação deficiente em nutrição. As enfermeiras, embora tenham cursado uma disciplina específica sobre nutrição durante a graduação, consideram que o ensino foi insatisfatório. Elas se con- tentam, menos do que os médicos, com os conhecimentos que possuem, julgando-os, em geral, também insatisfatórios.

VII) O nutricionista é o profissional habilitado por formação para desenvolver programas e ações de educação nutricional, e este fato é reconhecido pelas equipes e pelos usuários dos serviços.

VIII) Os nutricionistas precisam empreender uma luta corporativa no sentido de criar o espaço institucional, com base na lei que regulamenta a profissão. Essa luta tem importância social, na medida em que a sociedade necessita desse trabalho e essa necessidade é pouco reconhecida nas instâncias administrativas e governamentais.

IX) A questão do ensino de nutrição nos cursos superiores da área da saúde precisa ser discutida em todos os níveis - Ministério da Educação, universi dades e sociedades científicas.

X) O exílio pelo qual passou a educação nutricional ao longo de vinte anos não foi apenas no âmbito das organizações e serviços, mas também no do acadêmico, pois não há pesquisas e estudos desenvolvendo e aperfeiçoando teorias e métodos. É necessário investir em pesquisas neste campo e no aprimoramento dos profissionais que nele militam. Além disso, é imprescindível que os docentes que ministram essa disciplina nos cursos de graduação tenham formação específica na área.

\section{Referências}

ALVES, E. L., 1977. Nível alimentar, renda e educação. Revista ABIA/SAPRO, 30:17-44.

AM ERI CAN DIETETIC ASSOCIATION, 1994. Position paper: Nutrition - An essencial component of medical education. Journal of American Dietetic Association, 94:55-57.

BARDIN, L., (s/ d). Análise de Conteúdo. Lisboa: Editora 70.

BEHAR, M., 1991. Análisis crítico de los programas de nutrición aplicada en América Latina. Revista de Nutrição da PUCCAMP, 4:9-24.

BERGER, P. L. \& LUCKMANN, T., 1985. A Construção Social da Realidade. Petrópolis: Editora Vozes.

BOOG, M. C. F., RODRIGUES, K. R. M. \& SI LVA, S. M. F., 1988. Situação profissional dos nutricionistas egressos da PUCCAMP 1. Áreas de atuação, estabilidade, abandono da profissão, desemprego. Revista de Nutrição da PUCCAMP, 1:139-152. 
BOOG, M. C. F.; RONCADA, M. J.; STEWIEN, G., 1995. Ensino de nutrição nos cursos de Medicina e Enfermagem no Estado de São Paulo I - Cursos de Enfermagem. Acta Paulista de Enfermagem, 8:6675.

BOOG, M. C. F., 1996. Educação Nutricional em Serviços Públi cos de Saúde: Busca deEspaço para Ação Efetiva. Tese de Doutorado, São Paulo: Faculdade de Saúde Pública, Universidade de São Paulo.

BOOG, M. C. F., 1997. Educação nutricional: Passado, presente, futuro. Revista de Nutrição da PUCCAMP, 10:5-19.

BOSI, M. L. M., 1996. Profissi onalização e Con hecimento: A Nutrição em Questão. São Paulo: Editora HUCITEC.

CASTRO, C. M. \& PELIANO, A. M., 1985. Novos alimentos, velhos hábitos e o espaço para ações educativas. In: O Problema Alimentar no Brasil (C. M. Castro \& M. Coimbra, org.), pp. 195-213, São Paulo: Editora Almed.

CERQUEIRA, M. T., 1985. Educación en nutrición: Metas e metodología. Bol etín de la Oficina Sanitaria Panamericana, 99:498-509.

CHERY, A.; SABRY, J. H. \& WOOLCOTT, D. M., 1987. Nutrition knowledge and misconceptions of university students: 1971 vs. 1984. Journal of Nutrition Education, 19:237-241.

HAGUETTE, T. M. F., 1995. Metodologias Qualitativas na Sociologia. 4ạ Ed., Petrópolis: Editora Vozes.

HEIMBURGER, D. C.; ULLMAN, D. O.; RAMSEY, M. J.; WOOLDRIDGE, N. H.; EPPS, L. A.; HARDIN, M. \& HSU, C., 1994. Dietary habits of first year medical students assessed during clinical nutrition course. Nutrition, 10:214-221.

L'ABBATE, S., 1982. Fome e Desnutrição: Os Descaminhos da Política Social. Dissertação de Mestrado, São Paulo: Faculdade de Filosofia, Letras e Ciências Humanas, Universidade de São Paulo.

L'ABBATE, S., 1990. O Direi to à Saúde: Da Rei vindicação à Realização. Projetos de Política de Saúde em Campinas, São Paulo. Tese de Doutorado, São Paulo: Instituto de Filosofia, Letras e Ciências Humanas, Universidade de São Paulo.

LOURAU, A., 1975. A Análiselnstitucional. Petrópolis: Editora Vozes.

LÜDKE, M. \& ANDRÉ, M. E. D. A., 1986. Pesqui sa em Educação. São Paulo: Editora Pedagógica Universitária.

MINAYO, M. C. S., 1993. O Desafio do Conhecimento: Pesquisa Qualitativa em Saúde. São Paulo: Editora Hucitec/ Rio deJaneiro: Abrasco.
MODESTO, N., 1980. O Nutricionista Recém-Formado na Grande São Paulo e o Mercado de Trabalho. Dissertação de Mestrado, São Paulo: Faculdade de Saúde Pública, Universidade de São Paulo.

MONDINI, L. \& MONTEIRO, C. A., 1994. Mudanças no padrão de alimentação da população urbana brasileira (1962-1988). Revista de Saúde Pública, 28:433-439.

MONTEIRO, C. A.; MONDINI, L.; SOUZA, A. L. M. \& POPKIN, B. M., 1995. Da desnutrição para a obesidade: A transição nutricional no Brasil. In: VeIhos e Novos Males da Saúde no Brasil: A Evolução do País e de suas Doenças (C. A. Monteiro, org.), pp. 247-255, São Paulo: Editora Hucitec.

MONTEIRO, C. A.; IUNES, R. F. \& TORRES, A. M., 1995. A evolução do país e de suas doenças: síntese, hipóteses e explicações. In: Vel hos e Novos Males da Saúdeno Brasil: A Evolução do País e de suas Doenças (C. A. Monteiro, org. ), pp. 349-56, São Paulo: Editora Hucitec.

NÓBREGA, F. J. \& CAMPOS, A. L. R., 1996. Distúrbios Nutricionais eFraco Vínculo Mãe/Filho. São Paulo: Editora Revinter.

RITCHIE, J. A. S., 1951. Buenos Hábitos en la Alimentación - Métodos para Inculcarlos al Público. Estudios sobre Nutrición, 6. Roma: FAO (Food and Agriculture Organization).

SOLYM OS, G. M. B., 1997. A experiência vivida de mães de desnutridos: Um novo enfoque para intervenção em desnutrição infantil. In: Desnutrição Urbana no Brasil em um Período de Transi ção (A. L Sawaya, org.), pp. 127-153, São Paulo: Editora Cortez.

THIOLLENT, M., 1982. Crítica Metodológica, Investigação Social e Enquete Operária. 3a Ed., São Paulo: Editora Polis.

THIOLLENT, M., 1992. Metodologia da PesquisaAção. São Paulo: Cortez.

VIACAVA, F.; FIGUEIREDO, C. M. P. \& OLIVEIRA, W. A., 1983. A Desnutri ção no Brasil. Petrópolis: Editora Vozes.

WINICK, M., 1993. Nutrition education in medical schools. American Journal of Clinical Nutrition, 58:825-827.

WHO (World Health Organizaton), 1989. Study Group on Diet, Nutrition and Prevention of Non CommunicableDiseases. WHO Technical Report Series 797. Geneva: WHO. 